\title{
Performances of Shannon's Entropy Statistic in Assessment of Distribution of Data
}

\author{
Lorentz JÄNTSCHI ${ }^{1,2, *}$ and Sorana D. BOLBOACĂ ${ }^{3}$ \\ ${ }^{I}$ Technical University of Cluj-Napoca, Department of Physics and Chemistry, Muncii Blvd., No. 103-105, \\ 400641 Cluj-Napoca, Romania; lorentz.jantschi@gmail.com \\ ${ }^{2}$ Babeş-Bolyai University, Institute for Doctoral Studies, Kogălniceanu Street, No. 1, 400084 Cluj-Napoca, \\ Romania \\ ${ }^{3}$ Iuliu Haţieganu University of Medicine and Pharmacy, Department of Medical Informatics and Biostatistics, \\ Louis Pasteur Street, No. 6, 400349 Cluj-Napoca, Romania; sbolboaca@umfcluj.ro
}

\begin{abstract}
Statistical analysis starts with the assessment of the distribution of experimental data. Different statistics are used to test the null hypothesis $\left(\mathrm{H}_{0}\right)$ stated as Data follow a certain/specified distribution. In this paper, a new test based on Shannon's entropy (called Shannon's entropy statistic, H1) is introduced as goodness-of-fit test. The performance of the Shannon's entropy statistic was tested on simulated and/or experimental data with uniform and respectively four continuous distributions (as error function, generalized extreme value, lognormal, and normal). The experimental data used in the assessment were properties or activities of active chemical compounds. Five known goodness-of-fit tests namely Anderson-Darling, Kolmogorov-Smirnov, Cramér-von Mises, Kuiper V, and Watson $\mathrm{U}^{2}$ were used to accompany and assess the performances of $\mathrm{H} 1$.
\end{abstract}

Keywords: Shannon's entropy; statistic; continuous distribution; tests of goodness-of-fit.

\section{Introduction}

Different statistical tests are used to assess the agreement between theoretical probability models and measured data as an early step in the statistical analysis of experimental data. Kolmogorov-Smirnov (KS) $[1,2]$, Anderson-Darling (AD) [3,4], Pearson's Chi-square (CS) [5, 6], Cramér-von-Mises (CM) [7, 8], Shapiro-Wilk (SW) [9], Jarque-Bera (JB) [10-12], D'Agostino-Pearson [13], Lilliefors [14], or ShapiroFrancia (SF) [15] are just several tests that are classically implemented in commercial or noncommercial statistical software. KolmogorovSmirnov test is an order statistic that applied only on continuous distributions and is known to be less sensitive at the tails of the distribution [16]. Cramérvon-Mises [7,8] and $\mathrm{AD}[3,4]$ are refinements of the KS test that gives more weight to the tails [17], both tests being known as empirical distribution function (EDF) tests [18]. The critical values of $\mathrm{AD}$ test depend of the distribution that is tested. Pearson's Chi-square is an alternative to the K-S and A-D tests and its application is valid only if the values in each bin exceed five [18].

A small group of known theoretical probability distributions is usually used to describe or to approximate measured data, and the normal distribution is the most extensively used [19]. A parametric test is applied whenever data follow the normal distribution; otherwise a non-parametric test fit better to analyze the experimental data [20-22]. The normal distribution was by far the most studied. Monte Carlo experiments conducted on different sample sizes showed that SW test is the most powerful while opposite KS test is less powerful in the assessment of normal distribution [23]. Tui proved that Anderson-Darling assures validity and inference based on t-statistic compared with JB, SF, D'Agostino \& Pearson, and AD \& Lilliefors [24]. Islam applied stringency concept using the LR-tests to rank the normality tests and concluded that the best normality test is Anderson-Darling [25]. Mbah and Paothong used the expected p-value approach to characterize the normality test and showed that SF test is the best statistic in detecting deviation from normality when compared with $\mathrm{KS}, \mathrm{AD}, \mathrm{CM}$, Lilliefors, SW, CS, JB, and D'Agostino [26]. The scientific community shows attention not just to the assessment of the existing tests but also to development and validation of new tests. New approaches are reported to test certain distributions of measured/observed data, such as mean and quantile statistics based on the posterior predictive distribution [27], quantile-mean covariance [28], empirical distribution function [29], maximum entropy [30], Kullback-Leibler measure [31], sums of squares in decomposition of the Shapiro-Wilk-type statistic [32], Euclidean distance between sample

\footnotetext{
* Corresponding author. E-mail address: lorentz.jantschi@gmail.com; Tel.: +40-264-401-775 (Lorentz Jäntschi)
} 
elements for assessment of multivariate normality [33], or entropy estimators [34].

\section{Materials and methods}

\section{Shannon's Entropy Statistic}

The use of entropy as a test statistic is not a novel approach. Vasicek introduced in 1976 using entropy (the entropy of a normal distribution exceeds the values of any other distributions) a new goodness-offit test for normal distribution [35]. In the same year, Prescott tested the sensitivity of the normality test introduced by Vasicek and showed that the new test is less sensitive to the outliers [36]. The test introduced by Vasicek was also used to test other distributions (exponential, Gamma, uniform, $\operatorname{Beta}(2,1)$, and Cauchy) and obtained the highest power as compared with KS, CM, Kuiper, Watson $\mathrm{U}^{2}, \mathrm{AD}$, and $\mathrm{SW}$ tests for exponential $(85 \%)$ and for uniform distribution (44\%) while the smallest power was obtained for Cauchy distribution [36]. Different approaches were applied to estimate entropy and based on the new introduced estimators (e.g. modified Vasicek's estimator [37,38], Noughabi's entropy estimator [39]) new goodness-of-fit tests were developed and performances in testing the normal [40-42], lognormal [43], uniform [44-46], exponential [47], beta [47,48], Poisson [49], Weibull [43], Gamma [43], Pareto [50,51], Student and exponential distribution [52] were studied.

A statistic provides the correct conclusion in regards of null hypothesis $\left(\mathrm{H}_{0}\right)$ whenever data did not contain any outlier or extreme value [53]. A simple question arise: It is possible to construct a statistic able to provide the closest to the true answer in regards of testing the $\mathrm{H}_{0}$ ? A solution could be found by adapting the method proposed by Fisher [54] and discussed in the context of combining probability from multiple statistics [55]. An overall result based on several statistics is the best solution since most of the distributions has more than one degree of freedom. The degrees of freedom did not decrease by combining tests and could be considered independent since different tests implement different methods. In this regards, more than one statistics may fully cover the variation induced by the associated degrees of freedom.

Goodness-of-fit test based on entropy already showed to be less sensitive to the presence of extreme values or outliers [36] so combining its results with other goodness-of-fit tests could provide a good overall solution. Shannon's entropy generally refers to disorders or uncertainties [56] and here is introduced as statistic (H1) for evaluation of the distribution of experimental data. Its formula is given by $\mathrm{Eq}(1)$ :

$$
\mathrm{H} 1=-\sum_{\mathrm{i}=0}^{\mathrm{n}-1} \mathrm{f}_{\mathrm{i}} \cdot \ln \left(\mathrm{f}_{\mathrm{i}}\right)+\left(1-\mathrm{f}_{\mathrm{i}}\right) \cdot \ln \left(1-\mathrm{f}_{\mathrm{i}}\right)
$$

where $H 1$ is Shannon's entropy statistic, $n$ is the sample size, $i$ iterates (in ascending order) the observations in the sample, $f_{i}$ is the cumulative distribution function (CDF) associated with the observation (sorted in ascending order).

Shannon entropy was defined as a statistic for measurement of the distance between theoretical and observed distribution in a similar manner as other statistics (see Eq (2)-Eq (6)).

Several specific features made the Shannon's statistic enough different by all other investigated statistics. Shannon's statistic is calculated without sorting the CDF (cumulative distribution function) values, as other statistics need. Thus, Shannon's statistic is a 'clutter' statistics in the perfect agreement with the basic concept of entropy as a measure of disorder. The Shannon's approach additively cumulates the entropy of each CDF value from the binary division that is constructed in the probability space of $[0,1]$.

The algorithm presented in Figure 1 was applied for $\mathrm{H} 1$ statistic.

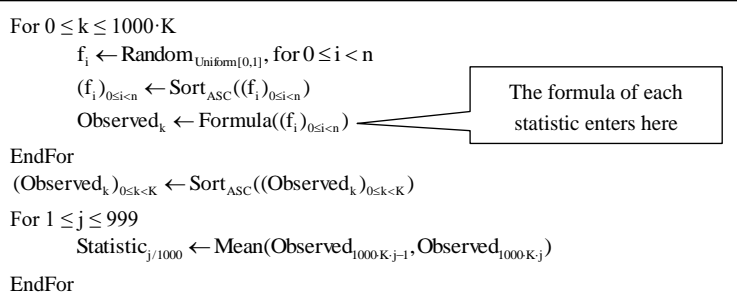

Figure 1. The steps applied to build the probability association map for the $\mathrm{H} 1$ statistic. The $K$ was set to a large numeric value, e.g. 10,000 as presented below, $k$ iterates the domain defined by 0 and $K$, and $j$ iterates the control points of probability thresholds $p_{j}=j / 1,000$, e.g. $0.001,0.002, \ldots, 0.999$.

The algorithm presented in Figure 1 worked with a fixed value of the sample size $(n)$ but can also be use by successive iterations for the value of $n$ starting with $n=2$. The large $K$ value and eventually repeated resampling are used for increasing the resolution of the statistic's values. For the same purpose, for a value $0 \leq x \leq 1$ the random is conducted in two steps, first for mantissa $((10,000+\operatorname{Random}(90,000)) / 100,000)$, and second for exponent (repeat $\mathrm{k}:=\operatorname{Random}(10)$; if $(\mathrm{k}=0)$ then $\mathrm{p}[\mathrm{i}]:=\mathrm{p}[\mathrm{i}] / 10$; until $(\mathrm{k}>0))$. Furthermore, Mersenne Twister method [57] was involved to simulate randomness. The inverse of the statistic probability function from the above-provided algorithm was used to find the answer for $\mathrm{H}_{0}$ by $\mathrm{H} 1$ statistic. 


\section{Evaluation Methodology}

\section{Comparison Statistics}

Five goodness-of-fit tests were also applied for each investigated null hypothesis:

- $\quad$ Anderson-Darling statistic (AD) $[3,4]$ :

$$
A D=-n-\frac{1}{n} \sum_{i=0}^{n-1}(2 \cdot i+1) \cdot \ln \left(f_{i} \cdot\left(1-f_{n-1-i}\right)\right)
$$

- Kolmogorov-Smirnov statistic (KS) $[1,2]$ :

$$
\mathrm{KS}=\sqrt{\mathrm{n}} \cdot \max _{0 \leq \mathrm{i} \leq \mathrm{n}-1}\left(\mathrm{f}_{\mathrm{i}}-\frac{\mathrm{i}}{\mathrm{n}}, \frac{\mathrm{i}+1}{\mathrm{n}}-\mathrm{f}_{\mathrm{i}}\right)
$$

- $\quad$ Cramér-von Mises statistic (CM) [7,8]:

$$
\mathrm{CM}=\frac{1}{12 \cdot \mathrm{n}}+\sum_{\mathrm{i}=0}^{\mathrm{n}-1}\left(\frac{2 \mathrm{i}+1}{2 \cdot \mathrm{n}}-\mathrm{f}_{\mathrm{i}}\right)^{2}
$$

- $\quad$ Kuiper V statistic (KV) [58]:

$$
\mathrm{KV}=\sqrt{\mathrm{n}} \cdot\left(\max _{0 \leq \mathrm{i} \leq \mathrm{n}-1}\left(\mathrm{f}_{\mathrm{i}}-\frac{\mathrm{i}}{\mathrm{n}}\right)+\max _{0 \leq \mathrm{i} \leq \mathrm{n}-1}\left(\frac{\mathrm{i}+1}{\mathrm{n}}-\mathrm{f}_{\mathrm{i}}\right)\right)
$$

- Watson $\mathrm{U}^{2}$ statistic (WU) [59]:

$$
\mathrm{WU}=\frac{1}{12 \cdot \mathrm{n}}+\sum_{\mathrm{i}=0}^{\mathrm{n}-1}\left(\frac{2 \mathrm{i}+1}{2 \cdot \mathrm{n}}-\mathrm{f}_{\mathrm{i}}\right)^{2}+\mathrm{n}\left(\frac{1}{2}-\frac{1}{\mathrm{n}} \sum_{\mathrm{i}=0}^{\mathrm{n}-1} \mathrm{f}_{\mathrm{i}}\right)^{2}
$$

where $A D$ is the statistic of the Anderson-Darling test, $K S$ is the statistic of the Kolmogorov-Smirnov test, $C M$ is the statistic of the Cramér-von Mises test, $K V$ is the statistic of the Kuiper $\mathrm{V}$ test, $W U$ is the statistic of the Watson $\mathrm{U}^{2}$ test, $n$ is the sample size, $i$ iterates (in ascending order) the observations in the sample, $f_{i}$ is the cumulative distribution function (CDF) associated with the observation (sorted in ascending order).

\section{Simulated Datasets}

A simple random technique was used to generate forty-five samples of data following uniform distribution with volumes equal with 15, 20, 30, 40, and 50. Note that even this method is standardized operates with the same string of probabilities, case which is not seen when experimental data are investigated. These simulated datasets were used to characterize the new statistic (H1) as compared with statistics from Eq (2)-Eq (6).

\section{Experimental Datasets}

Measured/observed properties/activities on a series of chemical compounds with sample size from 13 to 1714 were used to assessment the Shannon's statistic. The main characteristics of the datasets included in the evaluation are provided in Table 1.

Four statistic one-tailed null hypotheses $\left(\mathrm{H}_{0}\right)$ were evaluated on experimental data:

1. $\mathrm{H}_{0}$ : The experimental data follow the error distribution

2. $\mathrm{H}_{0}$ : The experimental data follow the generalized extreme value distribution

3. $\mathrm{H}_{0}$ : The experimental data follow the lognormal

\begin{tabular}{|c|c|c|c|c|}
\hline Set & Compounds & Property/Activity & $\mathbf{n}$ & Ref \\
\hline 01 & phenols & antioxidant activity & 42 & {$[60,61]$} \\
\hline 02 & drug-like compounds & blood-brain barrier permeability & 129 & [62] \\
\hline 03 & estrogen receptors binders & binding activity & 144 & [63] \\
\hline 04 & pure chemicals & heat of combustion & 1714 & [64] \\
\hline 05 & different active compounds & carcinogenicity (LD50) & 39 & [65] \\
\hline 06 & nitrocompounds & carcinogenic potency & 55 & [66] \\
\hline 07 & substituted anilines and phenols & toxicity to V.fischeri & 57 & [67] \\
\hline 08 & & toxicity to P. subcapitata & 58 & [67] \\
\hline 09 & phenols & toxicity to Tetrahymena pyriformis & 250 & [68] \\
\hline 10 & $\begin{array}{c}\text { deacetylase LpxC-2-aryloxazolines, aroylserines, } \\
\text { and 2-arylthiazolines }\end{array}$ & inhibitors on Pseudomonas aeruginosa & 51 & [69] \\
\hline 11 & LpxC inhibitors & inhibitory activity on gram-negative & 41 & [70] \\
\hline 12 & drug-like compounds & aqueous solubility & 166 & {$[71]$} \\
\hline 13 & sulfonamide & inhibition activity on carbonic anhydrase I & 40 & [72] \\
\hline 14 & & inhibition activity on carbonic anhydrase II & 40 & [72] \\
\hline 15 & & inhibition activity on carbonic anhydrase IV & 40 & [72] \\
\hline 16 & sulfonamides & $\mathrm{pKa}$ & 29 & [73] \\
\hline 17 & aromatic sulfonamides & inhibition activity on carbonic anhydrase II & 43 & [74] \\
\hline 18 & sulfonamides & inhibition activity on carbonic anhydrase II & 47 & {$[75]$} \\
\hline 19 & aromatic/heterocyclic sulfonamides & inhibition activity on carbonic anhydrase & 38 & [76-78] \\
\hline 20 & paclitaxel & antimitotic activity - B16 melanoma & 18 & [79] \\
\hline 21 & & antimitotic activity - MCF-7 & 17 & [79] \\
\hline 22 & & antimitotic activity - MCF-7-ADR & 16 & [79] \\
\hline 23 & taxoids & resistance index to $\mathrm{MCF}-7$ cell lines & 63 & {$[80]$} \\
\hline
\end{tabular}
distribution

4. $\mathrm{H}_{0}$ : The experimental data follow the normal distribution

Table 1. Characteristics of datasets used in the assessment ( $n=$ sample size). 
L. JÄNTSCHI and S. D. BOLBOACĂ / Ovidius University Annals of Chemistry 28 (2017) 30 - 42

\begin{tabular}{|c|c|c|c|c|}
\hline Set & Compounds & Property/Activity & $\mathbf{n}$ & Ref \\
\hline 24 & taxoids & cell growth inhibitory activity & 35 & [81] \\
\hline 25 & c-Src inhibitors & anticancer activity & 80 & [82] \\
\hline 26 & different compounds & boiling points & 196 & [83] \\
\hline 27 & & heats of vaporization & 19 & [83] \\
\hline 28 & carboquinone derivative & minimum effective dose & 37 & [84] \\
\hline 29 & cyclic peroxy ketals & half maximal inhibitory concentration & 18 & [85] \\
\hline 30 & organic pollutants & oxidative degradation & 33 & [86] \\
\hline 31 & & degradation & 33 & [87] \\
\hline 32 & (benzo)triazoles & fish toxicity & 97 & [88] \\
\hline 33 & thiophene and imidazopyridine derivatives & inhibition activity of the Polo-Like Kinase 1 & 136 & [89] \\
\hline 34 & substituted phenylaminoethanones & average antibacterial activity & 17 & {$[90]$} \\
\hline 35 & & average antifungal activity & 17 & {$[90]$} \\
\hline 36 & & average antimicrobial activity & 17 & {$[90]$} \\
\hline 37 & acetylcholinesterase inhibitors & inhibition activity & 110 & [91] \\
\hline 38 & antimony(III) complexes & glutathione reductase inhibitor & 14 & [92] \\
\hline 39 & polychlorinated diphenyl ethers & $298 \mathrm{~K}$ supercooled liquid vapor pressures & 107 & [93] \\
\hline 40 & & aqueous solubility & 107 & [93] \\
\hline 41 & hexahydroquinoline derivatives & calcium channel antagonist activity & 13 & [94] \\
\hline 42 & volatile organic compounds & draize eye score & 126 & {$[95,96]$} \\
\hline 43 & polychlorinated biphenyls & relative retention times & 209 & {$[97]$} \\
\hline 44 & drug-like compounds & blood-brain barrier permeability & 122 & [62] \\
\hline 45 & protein kinase inhibitors & inhibitory activity & 77 & [98] \\
\hline 46 & curcumin analogs & IL6 inhibition activity & 23 & [99] \\
\hline 47 & & TNF inhibition activity & 23 & [99] \\
\hline 48 & 4-aminoquinoline analogues & $\begin{array}{l}\text { antiplasmodial activity against chloroquine- } \\
\text { susceptible Plasmodium falciparum }\end{array}$ & 68 & {$[100]$} \\
\hline 49 & & $\begin{array}{c}\text { antiplasmodial activity chloroquine- resistant } \\
\text { Plasmodium falciparum }\end{array}$ & 68 & {$[100]$} \\
\hline 50 & nitrofuranyls & antitubercular agents & 110 & {$[101]$} \\
\hline
\end{tabular}

B16 melanoma = a murine tumor cell line; MCF-7 = a breast cancer cell line;

IL6 = Interleukin 6; TNF = Tumor necrosis factor

\section{Evaluation Approach}

The approach presented in Figure 2 was used to assess the proposed Shannon's entropy statistic. The values of $\mathrm{CDF}$ (cumulative distribution function) were calculated with EasyFit program (MathWave Technologies) for both simulated and experimental/observed datasets and each investigated distribution.

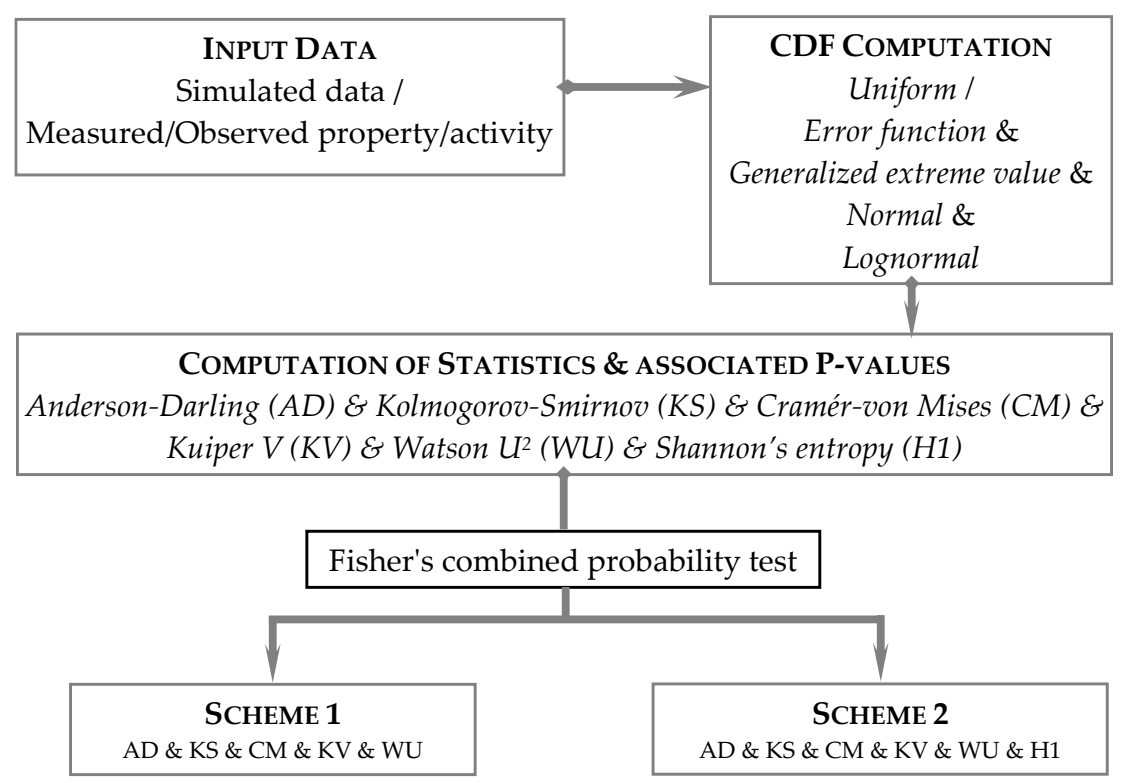

Figure 2. Flowchart illustrating the steps involved in assessment of Shannon's statistic. 
The computation of investigated statistics and of the associated p-values was done for each distribution and each dataset using the algorithm of the statisticprobability association map (Figure 1) and several *.php programs:

- Anderson-Darling (AD):

http://l.academicdirect.org/Statistics/tests/AD/

- Kolmogorov-Smirnov (KS): http://l.academicdirect.org/Statistics/tests/KS/

- Cramér-von Mises (CM): http://l.academicdirect.org/Statistics/tests/CM/

- $\quad$ Kuiper V (KV):

http://l.academicdirect.org/Statistics/tests/KV/

- Watson $\mathrm{U}^{2}(\mathrm{WU})$ :

http://l.academicdirect.org/Statistics/tests/WU/

- Shannon's entropy (H1):

http://l.academicdirect.org/Statistics/tests/H1/

The Fisher's combined probability test [54] was used to control the error rates using an adjusted significance level to diminish the possible influence of the positively correlated tests. All possible pairs of comparison adjust the significance level as $\alpha^{*}=$ $\alpha /[q \cdot(q-1) / 2]$, where $q=$ the number of the tests. Two different schemes were used to test the contribution of $\mathrm{H} 1$ to the overall conclusion relating $\mathrm{H}_{0}$. The first one (scheme 1) includes all statistics excepting the $\mathrm{H} 1$ $\left(\alpha_{1}^{*}=0.0050\right.$, and the second one (scheme 2) includes all investigated statistics, inclusive $\mathrm{H} 1\left(\alpha_{2}{ }^{*}\right.$ $=0.0033)$. Despite the fact that the input data are the same, each statistic $(\operatorname{Eq}(1)-\operatorname{Eq}(6))$ had its proper formula, formulas that are independent from each other as proved by Dijkstra [102].

\section{Results and discussions}

\section{Results on Simulated Data}

The uniform distribution was rejected at least one out of 45 runs by all investigated statistics for $n=15$, 20, 30, 40, and 50 (Table 2).

Table 2. Results on simulated data: number of individual rejections and the combined tests rejections.

\begin{tabular}{|c|c|c|c|c|c|c|c|c|}
\hline \multirow{2}{*}{$n$} & \multicolumn{6}{|c|}{$H_{0}$ : Data follow uniform distribution. $H_{0}$ rejection $(\alpha=5 \%)$} & \multirow{2}{*}{$\begin{array}{c}\text { Scheme 1 } \\
\left(\alpha^{*}=0.50 \%\right)\end{array}$} & \multirow{2}{*}{$\begin{array}{c}\text { Scheme 2 } \\
\left(\alpha^{*}=0.33 \%\right)\end{array}$} \\
\hline & $\mathrm{AD}, \mathbf{n}(\%)$ & $\mathbf{K S}, \mathbf{n}(\%)$ & CM, n (\%) & $\mathbf{K V}, \mathbf{n}(\%)$ & WU, n $(\%)$ & H1, n $(\%)$ & & \\
\hline 15 & $2(4.44)$ & $3(6.67)$ & $2(4.44)$ & $1(2.22)$ & $1(2.22)$ & $4(8.89)$ & $5(11.11)$ & $8(17.78)$ \\
\hline 20 & $1(2.22)$ & $2(4.44)$ & $0(0.00)$ & $3(6.67)$ & $4(8.89)$ & $2(4.44)$ & $8(17.78)$ & $7(15.56)$ \\
\hline 30 & $3(6.67)$ & $4(8.89)$ & $3(6.67)$ & $3(6.67)$ & $2(4.44)$ & $3(6.67)$ & $2(4.44)$ & $2(4.44)$ \\
\hline 40 & $4(8.89)$ & $3(6.67)$ & $2(4.44)$ & $1(2.22)$ & $2(4.44)$ & $1(2.22)$ & $1(2.22)$ & $1(2.22)$ \\
\hline 50 & $3(6.67)$ & $2(4.44)$ & $1(2.22)$ & $4(8.89)$ & $4(8.89)$ & $2(4.44)$ & $2(4.44)$ & $2(4.44)$ \\
\hline
\end{tabular}

$\mathrm{AD}=$ Anderson-Darling, $\mathrm{KS}=$ Kolmogorov-Smirnov, $\mathrm{CM}=$ Cramér-von Mises, $\mathrm{KV}=$ Kuiper $\mathrm{V}, \mathrm{WU}=\mathrm{W}$ atson $\mathrm{U}^{2}, \mathrm{H} 1=$ Shannon

Overall, the rejection of $\mathrm{H}_{0}$ by the combined test of significance is observed when three or more test individually rejected the $\mathrm{H}_{0}$ and this behavior is the same with or without the inclusion of $\mathrm{H} 1$ statistic. In some cases, certain goodness-of-fit test (such as KS for $\mathrm{n}=15,20$, WU for $\mathrm{n}=20, \mathrm{H} 1$ for $\mathrm{n}=15$ ) test transmit its individual significance to the combined test.

\section{Results on Experimental Data}

Different behavior of $\mathrm{H} 1$ statistic is observed when the assessment is conducted on experimental data. The number of $\mathrm{H}_{0}$ rejections by each individual test varied from $0(\mathrm{H} 1)$ to $21(\mathrm{KV})$ and proved smallest when Shannon's entropy was used as statistics (Table 3). On average, the highest percentage of rejections was given by Kuiper $\mathrm{V}$ statistic and was closely followed by Watson $\mathrm{U}^{2}$ statistic.

The results presented in Table 3 shows that the trend of $\mathrm{H} 1$ statistic is not to reject the null hypothesis and this behavior can be explained by its formula (see $\mathrm{Eq}(1)$ ), leading to a test more tolerant to extreme values or outliers. This behavior could be either a disadvantage (the hypothesis of association is not rejected even if it is false) or an advantage (the presence of outliers, which in most of the cases are data collection accidents, make other statistics to reject the null hypothesis much easiest even if this hypothesis is true). Therefore, the proposed H1statistic is more tolerant to such errors.

Table 3. Reject $\mathrm{H}_{0}$ ? Number of rejections and associated percentage by statistics (at a significance level of $5 \%$ ).

\begin{tabular}{ccccccc}
\hline Distribution & AD, n (\%) & $\mathbf{K S}, \mathbf{n}(\boldsymbol{\%})$ & $\mathbf{C M}, \mathbf{n}(\%)$ & $\mathbf{K V}, \mathbf{n}(\boldsymbol{\%})$ & WU, n (\%) & H1, n (\%) \\
\hline error & $9(18.75)$ & $12(24.00)$ & $11(22.00)$ & $19(38.00)$ & $17(34.00)$ & $0(0.00)$ \\
generalized extreme value & $6(13.33)$ & $5(10.00)$ & $4(8.00)$ & $13(26.00)$ & $11(22.00)$ & $3(6.67)$ \\
lognormal & $4(8.00)$ & $7(14.00)$ & $4(8.00)$ & $18(36.00)$ & $16(32.00)$ & $3(6.00)$ \\
normal & $8(16.67)$ & $14(28.00)$ & $10(20.00)$ & $21(42.00)$ & $20(40.00)$ & $0(0.00)$ \\
\hline
\end{tabular}

$\mathrm{AD}=$ Anderson-Darling, $\mathrm{KS}=$ Kolmogorov-Smirnov, $\mathrm{CM}=$ Cramér-von Mises, $\mathrm{KV}=$ Kuiper $\mathrm{V}, \mathrm{WU}=\mathrm{Watson} \mathrm{U}^{2}$, $\mathrm{H} 1=$ Shannon 
Without any exception, the median of number of failure to reject the $\mathrm{H}_{0}$ (p-value > 0.05 for each individual test) was equal with the number of investigated tests ( 5 for scheme 1 , and 6 for scheme 2 , see Table 4). The variation of quartiles was more monotone when $\mathrm{H} 1$ was included in the combined test while the most heterogeneous behavior was seen when the normal distribution was investigated (Table 4). The inclusion of $\mathrm{H} 1$ statistic in assessment of distribution smoothest the characteristics of summary statistics for error, generalized extreme value, and lognormal distributions (see Table 4).

Table 4. Failed to reject $\mathrm{H}_{0}$ : median, inter-quartile ranges ( $1^{\text {st }}$ quartile $-3^{\text {rd }}$ quartile $)$, and perfect concordance between investigated scheme.

\begin{tabular}{|c|c|c|c|}
\hline Distribution & $\begin{array}{c}\text { Scheme 1 } \\
\text { median (Q1-Q3) }\end{array}$ & $\begin{array}{c}\text { Scheme 2 } \\
\text { median (Q1-Q3) }\end{array}$ & $\begin{array}{c}\text { Perfect concordance* between } \\
\text { schemes, no. (\% [95\% CI]) }\end{array}$ \\
\hline error & $5(3-5)$ & $6(4-6)$ & $30(60[46-74])$ \\
\hline generalized extreme value & $5(4-5)$ & $6(4-6)$ & $32(64[50-78])$ \\
\hline lognormal & $5(3-5)$ & $6(4-6)$ & $31(62[48-76])$ \\
\hline normal & $5(2-5)$ & $6(3-6)$ & $29(58[44-72])$ \\
\hline
\end{tabular}

* perfect concordance was defined as an agreement on $\mathrm{H}_{0}$ obtained between all tests in both scheme

( 5 tests in Scheme 1 and 6 tests in Scheme 2); 95\% CI = 95\% confidence interval

To identify the behavior of proposed $\mathrm{H} 1$ statistic, the absolute difference between $p$-value of this statistic and respectively $p$-value of each other investigated statistic were counted. The $p$-values of the $\mathrm{H} 1$ proved closest to Anderson-Darling p-value for error and normal distributions (Figure 3). In the assessment of generalized extreme value distribution, the p-values of the $\mathrm{H} 1$ proved closest to Kuiper V statistic (Figure 3).

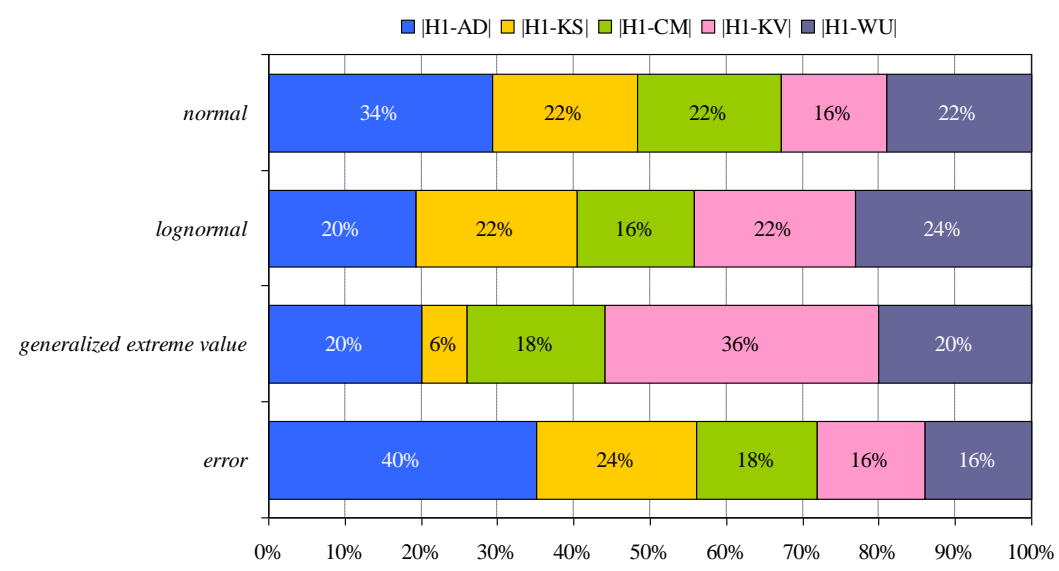

Figure 3. Minimum absolute difference between Shannon's (H1) p-value and p-values of other investigated statistics $(\mathrm{AD}=$ Anderson-Darling, $\mathrm{KS}=$ Kolmogorov-Smirnov, $\mathrm{CM}=$ Cramér-von Mises, $\mathrm{KV}=\mathrm{Kuiper} \mathrm{V}$, and $\mathrm{WU}=\mathrm{Watson} \mathrm{U}^{2}$ ).

With the exception of generalized extreme value distribution, for several datasets opposite conclusions regarding $\mathrm{H}_{0}$ was drawn by $\mathrm{H} 1$ statistic compared to all other investigated statistics (see Figure 4):
- Error distribution: set04, set26, and set34.

- Lognormal distribution: set04.

- Normal distribution: set04, set13, set14, set15, set26, and set34. 

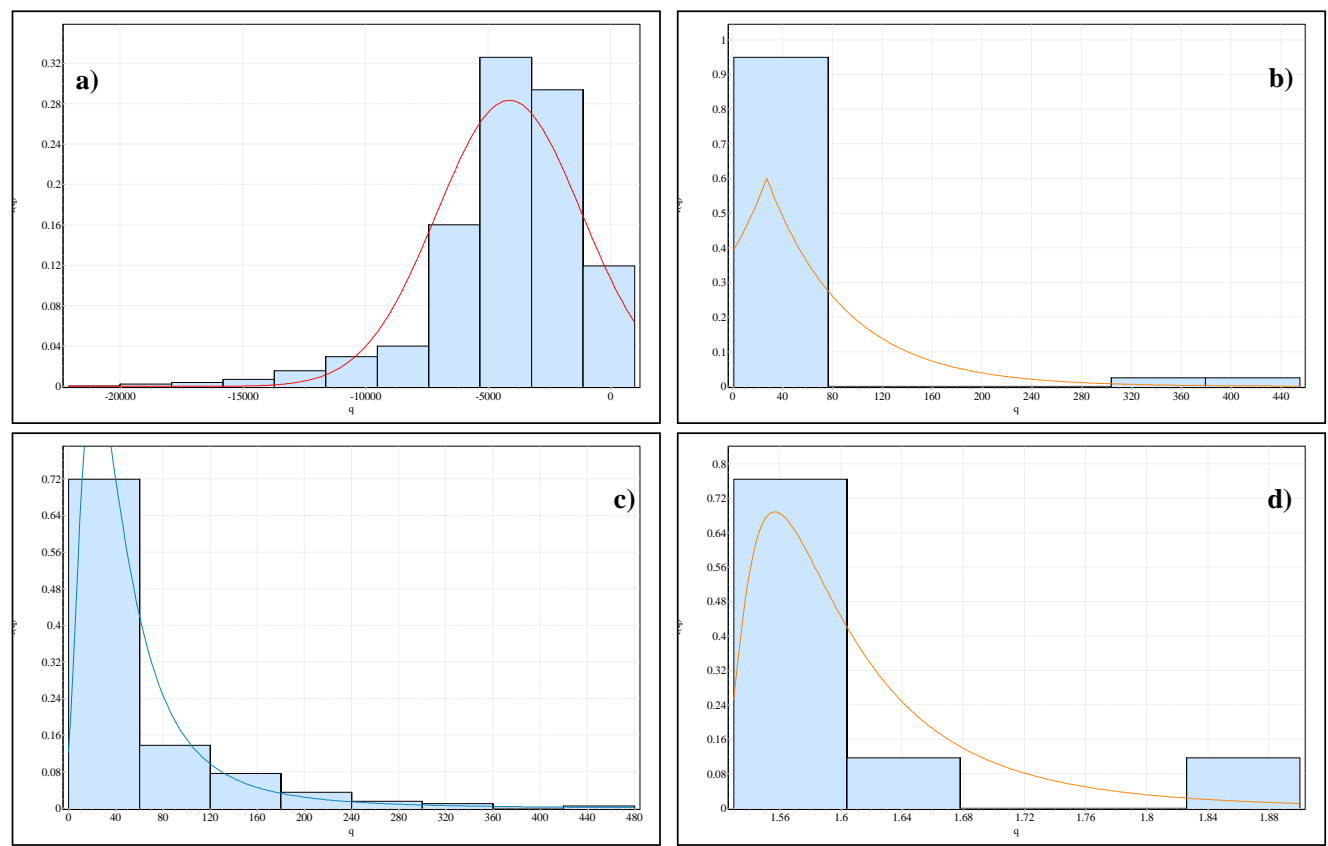

Figure 4. Shannon's opposite conclusion by example: a) set04 $\left(\mathrm{H}_{0}\right.$ rejected by $\mathrm{AD}=\mathrm{Anderson}-\mathrm{Darling}$, $\mathrm{KS}=$ Kolmogorov-Smirnov, $\mathrm{CM}=$ Cramér-von Mises, KV Kuiper $\mathrm{V}$, and WU=Watson $\mathrm{U}^{2}$ with $\mathrm{p}<0.0001$ while Shannon's statistic failed to reject $\mathrm{H}_{0}$ with $\mathrm{p}=0.4124$ for error distribution, $\mathrm{p}=0.9999$ for lognormal distribution, and $\mathrm{p}=0.9996$ for normal distribution); $\mathrm{b}$ ) set13 ( $\mathrm{H}_{0}$ rejected by $\mathrm{AD}, \mathrm{KS}, \mathrm{CM}, \mathrm{KV}$, and WU with $\mathrm{p}<0.0001$ while Shannon's statistic failed to reject $\mathrm{H}_{0}$ with $\mathrm{p}=0.9999$ for both error and normal distribution); c) set26 ( $\mathrm{H}_{0}$ rejected by $\mathrm{AD}, \mathrm{KS}, \mathrm{CM}, \mathrm{KV}$, and WU with $\mathrm{p}<0.0001$ while Shannon's statistic failed to reject $\mathrm{H}_{0}$ with $\mathrm{p}=0.8266$ for error distribution, $\mathrm{p}=0.9999$ for normal distribution); c) set $34\left(\mathrm{H}_{0}\right.$ rejected by $\mathrm{AD}, \mathrm{KS}, \mathrm{CM}, \mathrm{KV}$, and WU with $\mathrm{p}<0.04$ while Shannon's statistic failed to reject $\mathrm{H}_{0}$ with $\mathrm{p}=0.7878$ for error distribution, $\mathrm{p}=0.9423$ for normal distribution).

The overall combine test showed different results in the assessment of investigated distributions in both

investigated scheme when the analysis was conducted at adjusted significance levels (Table 5).

Table 5. Reject $\mathrm{H}_{0}$ ? Results of overall combine test of significance.

\begin{tabular}{ccccc}
\hline \multirow{2}{*}{ Distribution } & \multicolumn{2}{c}{ Scheme 1 } & \multicolumn{2}{c}{ Scheme 2 } \\
& no. & $\mathbf{\%}[\mathbf{9 5 \%} \mathbf{C I}]$ & no. & $\mathbf{\%}[\mathbf{9 5 \%} \mathbf{C I}]$ \\
\hline error & 14 & $28[16-42]$ & 11 & $22[30-58]$ \\
generalized extreme value & 7 & $14[6-26]$ & 5 & $10[4-22]$ \\
lognormal & 10 & $20[10-34]$ & 8 & $16[6-30]$ \\
normal & 16 & $32[20-46]$ & 15 & $30[18-44]$ \\
\hline
\end{tabular}

The inclusion of Shannon's statistic in the overall combine test has the smallest effect on the normal distribution, decreasing the rejection of $\mathrm{H}_{0}$ by $2 \%$, closely followed by generalized extreme value and lognormal distribution, decreasing the rejection of $\mathrm{H}_{0}$ by $4 \%$. The largest effect on the overall combined test induced by the $\mathrm{H} 1$ statistic was observed on error distribution, for which the decreasing the rejection of $\mathrm{H}_{0}$ by $6 \%$.

The concordance analysis (identical conclusion in both scenarios) shows the highest value for generalized extreme value distribution and the lowest value for normal distribution (Table 4). The value of probability associated with the rejection of the tested hypotheses systematically becomes larger in the scheme that includes the Shannon's entropy. The analysis of the Shannon's p-value relative to each other investigated statistics showed that these values are closest to Kuiper V for normal distribution, to Cramér-von Mises for lognormal distribution, to Kolmogorov-Smirnov for generalized extreme values distribution, and respectively to Kuiper V and Watson $\mathrm{U}^{2}$ for error distribution (see Figure 3 ).

In our analysis, we investigated how the combined test aggregate the information from different tests on the same $\mathrm{H}_{0}$. The main shortcoming of this approach is given by its asymmetrical sensitivity to small pvalues leading to the increase of type I error (incorrect rejection of $\mathrm{H}_{0}$ ) [103]. To diminish this shortcoming, an adjustment of the significance level was used, which could be seen as too conservative approach. However, this adjustment protects against the danger 
of overclaiming the significant results but with the cost of the possibly underclaiming. The problem of combining test of significance have been debated in the scientific literature mainly in regards of testing means [104-106]. Several methods have been introduced, the main known being the Stouffer's method (applied to one-tailed tests, also known as Ztransform test when the p-values are converted as normal standard derivatives [107]), and its derivate as weighted Z-method [108,109] mainly used in metaanalysis. Several different approaches have been published but no consensus exists in the scientific literature in regards of performances of these tests. Some authors sustain that the Fisher and/or its derivate [110] is the best while other authors sustained that other tests are best performing combined tests of significances [111,112]. However, our team works in this moment to identify as many as possible of such approach, to test them and to apply them to investigate the performances of $\mathrm{H} 1$ statistics. Furthermore, the new introduce H1 statistic need to be compared with other similar approaches that use

\section{References}

[1]. A. Kolmogorov, Sulla determinazione empirica di una legge di distribuzione, Giornale dell'Istituto Italiano degli Attuari 4 (1933) 8391.

[2]. N. Smirnov, Table for estimating the goodness of fit of empirical distributions, Annals of Mathematical Statistics 19 (1948) 279-281.

[3]. T.W. Anderson, D.A. Darling, Asymptotic theory of certain "goodness-of-fit" criteria based on stochastic processes, Annals of Mathematical Statistics 23 (1952) 193-212. DOI:

[4]. T.W. Anderson, D.A. Darling, A Test of Goodness-of-Fit, Journal of the American Statistical Association 49 (1954) 765-769.

[5]. K. Pearson, Contribution to the mathematical theory of evolution, II. Skew variation in homogenous material, Philosophical Transactions of the Royal Society of London 91 (1895) 343-414. DOI: 10.1098/rsta.1895.0010

[6]. K. Pearson, On the criterion that a given system of deviations from the probable in the case of a correlated system of variables is such that it can be reasonably supposed to have arisen from random sampling, Philosophical Magazine Series $5 \quad 50$ (1900) 157-175. DOI: 10.1080/14786440009463897

[7]. H. Cramér, On the composition of elementary errors, Skand Akt. 11 (1928) 141-180. DOI: 10.1080/03461238.1928.10416872

[8]. R.E. von Mises, Wahrscheinlichkeit, Statistik und Wahrheit, Julius Springer, Vienna, Austria (1928).

[9]. S.S. Shapiro, M.B. Wilk, An analysis of variance test for normality (complete samples), entropy as estimator in testing the distribution of data.

\section{Conclusions}

The contribution of the proposed $\mathrm{H} 1$ statistic to the final decision in assessment of the probability distributions has been investigated and a general tendency of the $\mathrm{H} 1$ to counterbalances the tendency of rejection the null hypothesis by the combined test of significance is observed on experimental data. The effect, however, could be insignificant since the practical outcome in the number of rejections is amended downwards in only 3 out of 50 cases. Furthermore, this effect of the $\mathrm{H} 1$ statistic must be assessed on different constrains and conditions.

Acknowledgments: No funds were received neither to conduct the research nor for covering the costs to publish in open access.

Conflicts of Interest: The authors declare no conflict of interest.

Biometrika 52 (1965) 591-611. DOI: $10.2307 / 2333709$

[10]. C.M. Jarque, A.K. Bera, Efficient tests for normality, homoscedasticity and serial independence of regression residuals, Economics Letters 6 (1980) 255-259. DOI: 10.1016/0165-1765(80)90024-5

[11]. C.M. Jarque, A.K. Bera, Efficient tests for normality, homoscedasticity and serial independence of regression residuals: Monte Carlo evidence, Economics Letters 7 (1981) 313-318. DOI: 10.1016/0165-1765(81)90035-5

[12]. C.M. Jarque, A.K. Bera, A test for normality of observations and regression residuals, International Statistical Review 55 (1987) 163172. DOI: $10.2307 / 1403192$

[13]. R.B. D'Agostino, A. Belanger, R.B.Jr. D'Agostino, A suggestion for using powerful and informative tests of normality, The American Statistician 44 (1990) 316-321. DOI: $10.2307 / 2684359$

[14]. H.W. Lilliefors, On the Kolmogorov-Smirnov for normality with mean and variance unknown, Journal of the American Statistical Association 62 (1967) 399-402. DOI: 10.2307/2283970

[15]. S.S. Shapiro, R.S. Francia, An approximate analysis of variance test for normality, Journal of the American Statistical Association 67 (1972) 215-216.

[16]. I.M. Chakravarti, R.G. Laha, J. Roy, Handbook of Methods of Applied Statistics, John Wiley and Sons 1 (1967) 392-394. 
[17]. T.B. Arnold, J.W. Emerson, Nonparametric Goodness-of-Fit Tests for Discrete Null Distributions, The R Journal 3/2 (2011) 34-39.

[18]. A. DasGupta, Asymptotic theory of statistics and probability, Springer, New York (2008).

[19]. C. Walck, Hand-book on STATISTICAL DISTRIBUTIONS for experimentalists. University of Stockholm: Internal Report SUFPFY/96-01, 1996, last modification 10 September 2007. Available online: http://www.stat.rice.edu/ dobelman/textfiles/D istributionsHandbook.pdf (accessed on 27 March 2017)

[20]. D. Curran-Everett, D.J. Benos, Guidelines for reporting statistics in journals published by the American Physiological Society, American Journal of Physiology. Endocrinology and Metabolism 287 (2004) E189-91. DOI: 10.1152/ajpendo.00213.2004

[21]. T.A. Lang, D.G. Altman, Basic Statistical Reporting for Articles Published in Biomedical Journals: The "Statistical Analyses and Methods in the Published Literature" or The SAMPL Guidelines". In: Smart, P.; Maisonneuve, H.; Polderman, A. (Eds). Science Editors' Handbook, European Association of Science Editors, 2013. Available online: http://www.equator-network.org/wpcontent/uploads/2013/07/SAMPL-Guidelines6-27-13.pdf (accessed on 27 March 2017)

[22]. B.M. Cesana, F. Cavaliere, Basics to perform and present statistical analyses in scientific biomedical reports Part 1, Minerva Anestesiologica 82 (2016) 822-826.

[23]. N.M. Razali, Y.B. Wah, Power comparison of Shapiro-Wilk, Kolmogorov-Smirnow, Lilliefors and Anderson-darling tests, Journal of Statistical Modeling and Analytics 2 (2011) 2133.

[24]. I. Tui, Normality Testing - A New Direction, International Journal of Business and Social Sciences 2 (2011) 115-118.

[25]. T.U. Islam, Stringency-based ranking of normality tests, Communications in Statistics: Simulation and Computation 46 (2017) 655668. DOI: 10.1080/03610918.2014.977916

[26]. A.K. Mbah, A. Paothong, Shapiro-Francia test compared to other normality test using expected p-value, Journal of Statistical Computation and Simulation 85 (2015) 3002-3016. DOI: $10.1080 / 00949655.2014 .947986$

[27] D. He, X. Xu, A goodness-of-fit testing approach for normality based on the posterior predictive distribution, Test 22 (2013) 1-18. DOI: $10.1007 / \mathrm{s} 11749-012-0282-6$

[28]. A.K. Bera, A.F. Galvao, L. Wang, Z. Xiao, A New Characterization of the Normal Distribution and Test for Normality, Econometric Theory 32 (2016) 1216-1252. DOI: $10.1017 / \mathrm{S} 026646661500016 \mathrm{X}$
[29]. H. Torabi, N.H. Montazeri, A. Grane, A test for normality based on the empirical distribution function, SORT 40 (2016) 55-87. DOI: 10.1007/978-3-642-04898-2_591

[30]. B. Choi, K. Kim, Testing goodness-of-fit for Laplace distribution based on maximum entropy, Statistics 40 (2006) 517-531. DOI: 10.1080/02331880600822473

[31]. A. Batsidis, P. Economou, G. Tzavelas, Tests of fit for a lognormal distribution, Journal of Statistical Computation and Simulation 86 (2016) 215-235. DOI: 10.1080/00949655.2014.1003138

[32]. T. Ledwina, G. Wyłupek, Detection of nonGaussianity, Journal of Statistical Computation and Simulation 85 (2015) 3480-3497. DOI: 10.1080/00949655.2014.983110

[33]. G.J. Székely, M.L. Rizzo, A new test for multivariate normality, Journal of Multivariate Analysis $93 \quad$ (2005) 58-80. DOI: 10.1016/j.jmva.2003.12.002

[34]. E. Zamanzade, N.R. Arghami, Testing normality based on new entropy estimators, Journal of Statistical Computation and Simulation 82 (2012) 1701-1713. DOI: 10.1080/00949655.2011.592984

[35] O. Vasicek, A test for normality based on sample entropy, Journal of the Royal Statistical Society. Series B (Methodological) 38 (1976) 54-59.

[36] P. Prescott, On a Test for Normality Based on Sample Entropy, Journal of the Royal Statistical Society. Series B (Methodological) 38 (1976) 254-256.

[37]. J.C. Correa, A new estimator of entropy, Communications in Statistics - Theory and Methods 24 (1995) 2439-2449. DOI: $10.1080 / 03610929508831626$

[38]. P. Crzcgorzewski, R. Wirczorkowski, Entropybased goodness-of-fit test for exponentiality, Communications in Statistics - Theory and Methods 28 (1999) 1183-1202. DOI: $10.1080 / 03610929908832351$

[39]. H.A. Noughabi, An estimator of entropy and its application in testing normality, Journal of Statistical Computation and Simulation 80 (2010) 1151-1162.

DOI: $10.1080 / 00949650903005656$

[40]. M. Bitaraf, M. Rezaei, F. Yousefzadeh, Test for normality based on two new estimators of entropy, Journal of Statistical Computation and Simulation 87 (2017) 280-294. DOI: 10.1080/00949655.2016.1208201

[41]. S. Park, A goodness-of-fit test for normality based on the sample entropy of order statistics, Statistics \& Probability Letters 44 (1999) 359363. DOI: 10.1016/S0167-7152(99)00027-9 
[42]. H.A. Noughabi, Two Powerful Tests for Normality, Annals of Data Science 3 (2016) 225-234. DOI: 10.1007/s40745-016-0083-y

[43]. S. Lee, A maximum entropy type test of fit: Composite hypothesis case, Computational Statistics \& Data Analysis $57\left({ }^{201} 3\right)^{5} 9-67 \cdot$ DOI: 10.1016/j.csda.2012.06.006

[44]. E.J. Dudewicz, E.C. van der Meulen, EntropyBased Tests of Uniformity, Journal of the American Statistical Association 76 (1981) 967974. DOI: $10.2307 / 2287597$

[45]. E. Zamanzade, N.R. Arghami, Testing normality based on new entropy estimators, Journal of Statistical Computation and Simulation 82 (2012) 1701-1713. DOI: $10.1080 / 00949655.2011 .592984$

[46]. E. Zamanzadea, Testing uniformity based on new entropy estimators, Journal of Statistical Computation and Simulation 85 (2014) 31913205. DOI: $10.1080 / 00949655.2014 .958085$

[47]. S. Lee, I. Vonta, A. Karagrigoriou, A maximum entropy type test of fit, Computational Statistics and Data Analysis 52 (2011) 2635-2643. DOI: 10.1016/j.csda.2011.03.012

[48]. D.V. Gokhale, On entropy-based goodness-offit tests, Computational Statistics \& Data Analysis 1 (1983) 157-165. DOI: 10.1016/01679473(83)90087-7

[49]. S. Lee, Goodness of fit test for discrete random variables, Computational Statistics \& Data Analysis $69 \quad$ (2014) 92-100. DOI: 10.1016/j.csda.2013.07.026

[50]. J. Lequesne, Entropy-based goodness-of-fit test: Application to the Pareto distribution, AIP Conference Proceedings 1553 (2013) 155-162. DOI: $10.1063 / 1.4819995$

[51]. B. Afhami, M. Madadi, Entropy-based goodness-of-fit tests for the Pareto I distribution, Communications in Statistics Theory and Methods 46 (2017) 3649-3666. DOI: $10.1080 / 03610926.2015 .1069350$

[52]. S. Lee, M. Kim, On entropy-based goodness-offit test for asymmetric Student-t and exponential power distributions, Journal of Statistical Computation and Simulation 87 (2017) 187197. DOI: $10.1080 / 00949655.2016 .1196690$

[53]. L. Jäntschi, S.D. Bolboacă, Distribution fitting 2. Pearson-Fisher, Kolmogorov-Smirnov, Anderson-Darling, Wilks-Shapiro, Kramervon-Misses and Jarque-Bera statistics, Bulletin of University of Agricultural Sciences and Veterinary Medicine Cluj-Napoca. Horticulture 66 (2009) 691-697.

[54]. R.A. Fisher, Questions and answers \#14, The American Statistician 2 (1948) 30-31.

[55]. S.D. Bolboacă, L. Jäntschi, A.F. Sestraş, R.E. Sestraş, Pamfil, D.C. Supplementary material of 'Pearson-Fisher chi-square statistic revisited', Information 2 (2011) 528-545. DOI: 10.3390/info2030528
[56]. C.E. Shannon, A Mathematical Theory of Communication, Bell System Technical Journal 27 (1948) 379-423. DOI: 10.1002/j.15387305.1948.tb01338.x

[57]. M. Matsumoto, T. Nishimura, Mersenne twister: a 623-dimensionally equidistributed uniform pseudo-random number generator, ACM Transactions on Modeling and Computer Simulation 8 (1998) 3-30.

[58]. N.H. Kuiper, Tests concerning random points on a circle, Proceedings of the Koninklijke Nederlandse Akademie van Wetenschappen, Series A 63 (1960) 38-47. DOI: 0.1016/S13857258(60)50006-0

[59]. J. Zar, Biostatistical analysis, $2^{\text {nd }}$ ed, PrenticeHall, Inc., Englewood Cliffs, NJ, USA (1984).

[60]. I. Mitra, A. Saha, K. Roy, Chemometric QSAR Modeling and In Silico Design of Antioxidant NO Donor Phenols, Scientia Pharmaceutica 79 (2011) 31-57. DOI: 10.3797/scipharm.1011-02.

[61]. C. Cena, D. Boschi, G.C. Tron, K. Chegaev, L. Lazzarato, A. Di Stilo, M. Aragno, R. Fruttero, A. Gasco, Development of a new class of potential antiatherosclerosis agents: NO-donor antioxidants, Bioorganic \& Medicinal Chemistry Letters 14 (2004) 5971-5974. DOI: 10.1016/j.bmcl.2004.10.006

[62]. S.D. Bolboacă, L. Jäntschi, Predictivity Approach for Quantitative Structure-Property Models. Application for Blood-Brain Barrier Permeation of Diverse Drug-Like Compounds, International Journal of Molecular Science 12 (2011) 4348-4364. DOI: 10.3390/ijms 12074348

[63]. J. Li, P. Gramatica, The importance of molecular structures, endpoints' values, and predictivity parameters in QSAR research: QSAR analysis of a series of estrogen receptor binders, Molecular Diversity 14 (2010) 687696. DOI: 10.1007/s11030-009-9212-2

[64]. F. Gharagheizi, A simple equation for prediction of net heat of combustion of pure chemicals, Chemometrics and Intelligent Laboratory Systems 91 (2008) 177-180. DOI: 10.1016/j.chemolab.2007.11.003

[65]. ChemIDPlus, ToxNet DATABSE. Available online: URL: http://chem.sis.nlm.nih.gov (accessed on 20 September 2016).

[66]. A. Morales Helguera, M.N.D.S. Cordeiro, M.A.C. Perez, R.D. Combes, M. Perez Gonzalez, QSAR modeling of the rodent carcinogenicity of nitrocompounds, Bioorganic \& Medicinal Chemistry 16 (2008) 3395-3407. DOI: $10.1016 /$ j.bmc.2007.11.029 
[67]. V. Aruoja, M. Sihtmäe, H.C. Dubourguier, A. Kahru, Toxicity of 58 substituted anilines and phenols to algae Pseudokirchneriella subcapitata and bacteria Vibrio fischeri: comparison with published data and QSARs, Chemosphere 84 (2011) 1310-1320. DOI: 10.1016/j.chemosphere.2011.05.023

[68]. Y.H. Zhao, X. Yuan, L.M. Su, W.C. Qin, M.H. Abraham, Classification of toxicity of phenols to Tetrahymena pyriformis and subsequent derivation of QSARs from hydrophobic, ionization and electronic parameters, Chemosphere 75 (2009) 866-871. DOI: 10.1016/j.chemosphere.2009.01.055

[69]. R.U. Kadam, N. Roy, Cluster analysis and twodimensional quantitative structure-activity relationship (2D-QSAR) of Pseudomonas aeruginosa deacetylase LpxC inhibitors, Bioorganic \& Medicinal Chemistry Letters 16 (2006) 5136-5143. DOI: 10.1016/j.bmcl.2006.07.041

[70]. J.B. Ghasemi, R. Safavi-Sohi, E.G. Barbosa, 4D-LQTA-QSAR and docking study on potent Gram-negative specific LpxC inhibitors: a comparison to CoMFA modeling, Molecular Diversity 16 (2012) 203-213.

[71]. P.R. Duchowicz, A. Talevi, L.E. Bruno-Blanch, E.A. Castro, New QSPR study for the prediction of aqueous solubility of drug-like compounds, Bioorganic \& Medicinal Chemistry 16 (2008) 7944-7955.

[72]. C.T. Supuran, B.W. Clare, Carbonic anhydrase inhibitors - part 57: Quantum chemical QSAR of a group of 1,3,4-thiadiazole- and 1,3,4thiadiazoline disulfonamides with carbonic anhydrase inhibitory properties, European Journal of Medicinal Chemistry 34 (1999) 4150. DOI: 10.1016/S0223-5234(99)80039-7

[73]. A.T. Balaban, P.V. Khadikar, C.T. Supuran, A. Thakur, M. Thakur, Study on supramolecular complexing ability vis-à-vis estimation of $\mathrm{pKa}$ of substituted sulfonamides: dominating role of Balaban index $(\mathrm{J})$, Bioorganic \& Medicinal Cemistry Letters 15 (2005) 3966-3973. DOI: 10.1016/j.bmcl.2005.05.136

[74]. G. Melagraki, A. Afantitis, H. Sarimveis, O. Igglessi-Markopoulou, C.T. Supuran, QSAR study on para-substituted aromatic sulfonamides as carbonic anhydrase II inhibitors using topological information indices, Bioorganic \& Medicinal Chemistry 14 (2006) 1108-1114. DOI: 10.1016/j.bmc.2005.09.038
[75]. E. Eroglu, Some QSAR studies for a group of sulfonamide Schiff base as carbonic anhydrase CA II inhibitors, International Journal of Molecular Sciences 9 (2008) 181-197.

[76]. L. Puccetti, G. Fasolis, D. Vullo, Z.H. Chohan, A. Scozzafava, C.T. Supuran, Carbonic anhydrase inhibitors. Inhibition of cytosolic/tumor-associated carbonic anhydrase isozymes I, II, IX, and XII with Schiff's bases incorporating chromone and aromatic sulfonamide moieties, and their zinc complexes, Bioorganic \& Medicinal Chemistry Letters 15 (2005) 3096-3101. DOI: 10.1016/j.bmcl.2005.04.055

[77]. C.T. Supuran, A. Scozzafava, A. Popescu, R. Bobes-Tureac, A. Banciu, G. Bobes-Tureac, M.D. Banciu, Carbonic anhydrase inhibitors. Part 43. Schiff bases derived from aromatic sulfonamides: towards more specific inhibitors for membrane-bound versus cytosolic isozymes, European Journal of Medicinal Chemistry 32 (1997) 445-452. DOI: 10.1016/S02235234(97)81681-9

[78]. J. Krungkrai, A. Scozzafava, R. Reungprapavut, S.R. Krungkrai, R. Rattanajak, S. Kamchonwongpaisand, C.T. Supuran, Carbonic anhydrase inhibitors. Inhibition of Plasmodium falciparum carbonic anhydrase with aromatic sulfonamides: towards antimalarials with a novel mechanism of action, Bioorganic \& Medicinal Chemistry 13 (2005) 483-489. DOI: 10.1016/j.bmc.2004.10.015

[79]. S. Mohanraj, M. Doble, 3-D QSAR Studies of Microtubule Stabilizing Antimitotic Agents Towards Six Cancer Cell Lines, QSAR \& Combinatorial Science 25 (2006) 952-960. DOI: 10.1002/qsar.200630029

[80]. P.P. Dong, Y.Y. Zhang, G.B. Ge, C.Z. Ai, Y. Liu, L. Yang, C.X. Liu, Modeling resistance index of taxoids to MCF-7 cell lines using ANN together with electrotopological state descriptors, Acta Pharmacologica Sinica 29 (2008) 385-396. DOI: 10.1111/j.17457254.2008.00746.x.

[81]. H. Morita, A. Gonda, L. Wei, K. Takeya, H. Itokawa, 3D QSAR Analysis of Taxoids from Taxus Cuspidata Var. Nana by Comparative Molecular Field Approach, Bioorganic \& Medicinal Chemistry Letters 7 (1997) 23872392. DOI: 10.1016/S0960-894X(97)00439-3

[82]. N.C. Comelli, E.V. Ortiz, M. Kolacz, A.P. Toropova, A.A. Toropov, P.R. Duchowicz, E.A. Castro, Conformation-independent QSAR on c- 
Src tyrosine kinase inhibitors, Chemometrics and Intelligent Laboratory Systems 134 (2014) 47-52. DOI: 10.1016/j.chemolab.2014.03.003

[83]. M.W.Jr. Chase, C.A. Davies, J.R.Jr. Downey, D.J. Frurip, R.A. McDonald, A.N. Syverud, JANAF Thermochemical Tables, Third Edition, Journal of Physical and Chemical Reference Data 14(1985) pp. 1856.

[84]. S.D. Bolboacă, L. Jäntschi, Comparison of Quantitative Structure-Activity Relationship Model Performances on Carboquinone Derivatives, The Scientific World Journal 9 (2009) 1148-1166. DOI: 10.1100/tsw.2009.131

[85]. K. Roy, Chapter 7 - Validation of QSAR Models. In: Understanding the Basics of QSAR for Applications in Pharmaceutical Sciences and Risk Assessment, AcademicPres, pp. 231-289 (2015).

[86]. L. Jia, Z. Shen, W. Guo, Y. Zhang, H. Zhu, W. Jia, M. Fan, QSAR models for oxidative degradation of organic pollutants in the Fenton process, Journal of the Taiwan Institute of Chemical Engineers 46 (2015) 140-147. DOI: 10.1016/j.jtice.2014.09.014

[87]. H. Zhu, W. Guo, Z. Shen, Q. Tang, W. Ji, L. Jia, QSAR models for degradation of organic pollutants in ozonation process under acidic condition, Chemosphere 119 (2015) 65-71. DOI: 10.1016/j.chemosphere.2014.05.068

[88]. S. Cassani, S. Kovarich, E. Papa, P.P. Roy, L. van der Wal, P. Gramatica, Daphnia and fish toxicity of (benzo)triazoles: Validated QSAR models, and interspecies quantitative activityactivity modeling, Journal of Hazardous Materials 258-259 (2013) 50-60. DOI: 10.1016/j.jhazmat.2013.04.025

[89]. N.C. Comelli, P.R. Duchowicz, E.A. Castro, QSAR models for thiophene and imidazopyridine derivatives inhibitors of the Polo-Like Kinase 1, European Journal of Pharmaceutical Sciences 62 (2014) 171-179. DOI: 10.1016/j.ejps.2014.05.029

[90]. D. Verma, P. Kumar, B. Narasimhan, K. Ramasamy, V. Mani, R.K. Mishra, A.B.A. Majeed, Synthesis, antimicrobial, anticancer and QSAR studies of 1-[4-(substituted phenyl)2-(substituted phenyl azomethyl)-benzo[b][1,4]diazepin-1-yl]-2-substituted

phenylaminoethanones, Arabian Journal of Chemistry (2015)

DOI: 10.1016/j.arabjc.2015.06.010

[91]. M.D. Vitorović-Todorović, I.N. Cvijetić, I.O. Juranić, B.J. Drakulić, The 3D-QSAR study of
110 diverse, dual binding, acetylcholinesterase inhibitors based on alignment independent descriptors (GRIND-2). The effects of conformation on predictive power and interpretability of the models, Journal of Molecular Graphics and Modelling 38 (2012) 194-210. DOI: 10.1016/j.jmgm.2012.08.001

[92]. T. Tunç, Y. Koç, L. Açık, M.S. Karacan, N. Karacan, DNA cleavage, antimicrobial studies and a DFT-based QSAR study of new antimony(III) complexes as glutathione reductase inhibitor, Spectrochimica Acta Part A: Molecular and Biomolecular Spectroscopy 136 (2015) 1418-1427.

DOI: 10.1016/j.saa.2014.10.030

[93]. X. Hui-Ying, Z. Jian-Wei, H. Gui-Xiang, W. Wei, QSPR/QSAR models for prediction of the physico-chemical properties and biological activity of polychlorinated diphenyl ethers (PCDEs), Chemosphere 80 (2010) 665-670.

[94]. R. Miri, K. Javidnia, H. Mirkhani, B. Hemmateenejad, Z. Sepeher, M. Zalpour, T. Behzad, M. Khoshneviszadeh, N. Edraki, A.R. Mehdipour, Synthesis, QSAR and Calcium Channel Modulator Activity of New Hexahydroquinoline Derivatives Containing Nitroimidazole, Chemical Biology \& Drug Design 70 (2007) 329-336. DOI: 10.1111/j.1747-0285.2007.00565.x

[95]. M.H. Abraham, R. Kumarsingh, J.E. ComettoMuniz, W.S. Cain, A Quantitative Structure \pm Activity Relationship (QSAR) for a Draize Eye Irritation Database, Toxicology in Vitro 12 (1998) 201-207. DOI: 10.1016/S08872333(97)00117-3

[96]. S.D. Bolboacă, L. Jäntschi, From molecular structure to molecular design through the Molecular Descriptors Family Methodology, In: Castro, E.A. (Ed.), QSPR-QSAR Studies on Desired Properties for Drug Design. Research Signpost, Transworld Research Network, pp. 117-166 (2010).

[97]. L. Jäntschi, S.D. Bolboacă, M.V. Diudea, Chromatographic Retention Times of Polychlorinated Biphenyls: from Structural Information to Property Characterization, International Journal of Molecular Sciences 8 (2007) 1125-1157.

[98]. L. Quesada-Romero, K. Mena-Ulecia, W. Tiznado, J. Caballero, Insights into the Interactions between Maleimide Derivates and GSK3 $\beta$ Combining Molecular Docking and 
QSAR, PLoS ONE 9 (2014) e102212. DOI:

10.1371/journal.pone.0102212

[99]. C. Zhao, Y. Zhang, P. Zou, J. Wang, W. He, D. Shi, H. Li, G. Liang, S. Yang, Synthesis and biological evaluation of a novel class of curcumin analogs as anti-inflammatory agents for prevention and treatment of sepsis in mouse model, Drug Design, Development and Therapy 9 (2015) 1663-1678.

DOI: 10.2147/DDDT.S75862

[100].S.J. Hocart, H. Liu, H. Deng, D. De, F.M. Krogstad, D.J. Krogstad, 4-Aminoquinolines Active against Chloroquine-Resistant Plasmodium falciparum: Basis of Antiparasite Activity and Quantitative Structure-Activity Relationship Analyses, Antimicrobial Agents and Chemotherapy 55 (2011) 2233-2244. DOI: 10.1128/AAC.00675-10

[101].K.E. Hevener, D.M. Ball, J.K. Buolamwini, R.E. Lee, Quantitative structure-activity relationship studies on nitrofuranyl antitubercular agents, Bioorganic \& Medicinal Chemistry 16 (2008) 8042-8053. DOI: 10.1016/j.bmc.2008.07.070

[102].R.L. Dykstra, On dependent tests of significance in the multivariate analysis of variance, The Annals of Statistics 7 (1979) 459461.

[103].R.A. Fisher, Statistical Methods for Research Workers, Oliver and Boyd, Edinburgh, Scotland (1932)

[104].E.S. Pearson, The Probability Integral Transformation for Testing Goodness of Fir and Combining Independent Tests of Significance, Biometrika 30 (1938) 134-148. DOI: $10.2307 / 2332229$
[105].W.A. Wallie, Compounding Probabilities from Independent Significance Tests, Econometrica 10 (1942) 229-248. DOI: 10.2307/1905466

[106].A. Birnbaum, Combining Independent Tests of Significance, Journal of the American Statistical Association 49 (1954) 559-574. DOI: $10.2307 / 2281130$

[107].S.A. Stouffer, E.A. Suchman, L.C. De Vinney, S.A. Star, R.M.Jr. Williams, The American Soldier: Adjustment during army life, Princeton University Press, Princeton, New York (1949).

[108].F. Mosteller, R.R. Bush, Selected quantitative techniques, In: G. Lindzey, (Ed.) Handbook of Social Psychology, Addison-Wesley, Cambridge, 1 (1954) 289-334.

[109].T. Liptak, On the combination of independent tests, Magyar Tudományos Akadémia Matematikai Kutató Intézete 3 (1958) 171-197.

[110].Madhusudan Bhandary, Xuan Zhang, Comparison of Several Tests for Combining Several Independent Tests, Journal of Modern and Applied Statistical Methods 10 (2011) 436444.

[111].E. Levonian, An Alternative to the Fisher and Pearson Methods for Combining Tests of Significance, Perceptual and Motor Skills 61 (1985) 967-983.

[112].M.C. Whitlock, Combining probability from independent tests: the weighted Z-method is superior to Fisher's approach, Journal of Evolutionary Biology 18 (2005) 1368-1373. DOI: $10.1111 / \mathrm{j} .1420-9101.2005 .00917 . x$

Received: 13.06.2017 Received in revised form: 25.07.2017 Accepted: 26.07.2017 